\section{Money matters}

\section{David Pearce}

The State of Humanity. Edited by Julian L. Simon. Blackwell: 1996. Pp. 694. £55, $\$ 54.95$ (hbk); $£ 16.99$, \$22.95 (pbk).

From Care to Action. By Martin Holdgate. Earthscan: 1996. Pp. 346. £35, \$56 (hbk); £14.95, \$26 (pbk). Distributed in the United States by Island.

As the millennium approaches, it is time for reflection and anticipation. Some might argue that humankind has made such a mess of things that it cannot seriously expect to survive for much longer, at least in current social forms. Only those who believe in some evolutionary goal for humans may be upset by such a prospect: after all, the end of humankind will not be the end of all species, although many may go down in the process. Earth surely transcends the human race. Others are less doleful and seem divided into two camps: those who recognize there is a serious problem, but who believe there is a chance of a sustainable and reasonably tolerable future if only we act positively and now; and those who deny there is a problem, that scaremongers have exaggerated the issues and that the many social and economic feedback mechanisms will correct, sooner or later, any problems that do arise. Call them the concerned and the benign optimists respectively. Martin Holdgate belongs to the former group, Julian Simon to the latter. These two volumes could hardly be more different.

Simon's book has nearly 60 contributions from 64 authors, 62 of them from the United States. Around half the contributions are on environmental and natural resource problems, but there are essays on, among other things, smoking, murder, inequality in the United States, poverty and homelessness. The US bias shows. For example, Bruce Gardner and Theodore Schultz's essay on soil erosion relates to the United States, not developing countries, where many would argue the issue is far more serious. Laurence Kulp's essay on acid rain declares that it is "clearly beneficial" to crops in the United States, and has only "small negative effects" on buildings and materials, neither of which conclusion is consistent with European studies. Occasional forays into non-US evidence also reveal the risks of a dominant US authorship: thus William Baumol and William Oates, both immensely distinguished economists, rightly applaud the restored water quality of the River Thames in the south of England, but might be surprised to learn that, at least in terms of length of rivers classified as clean, there has not been a very discernible improvement over the past 30 years in the other rivers of England and Wales.

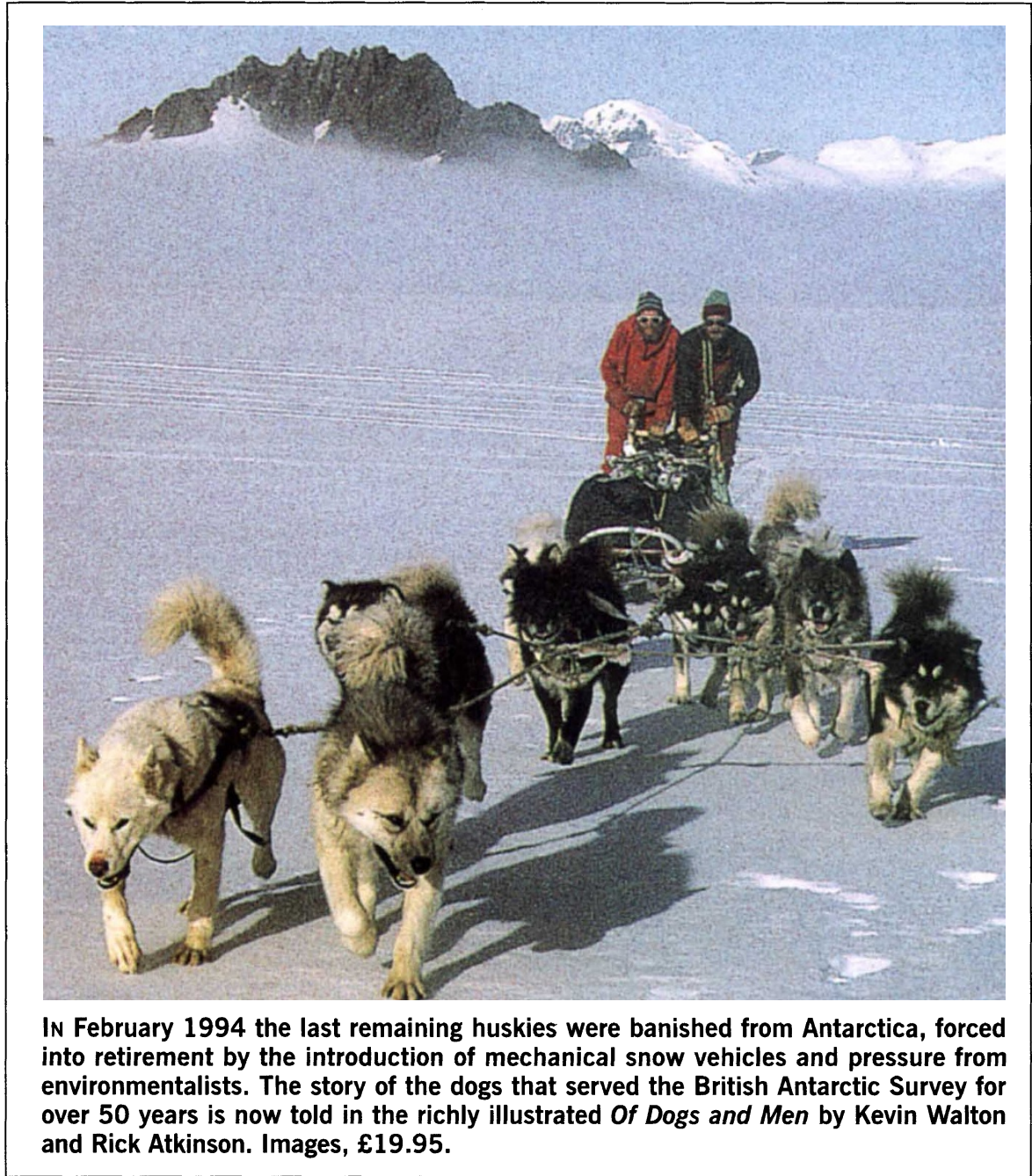

Those who know Simon's previous work will not be surprised at his upbeat introduction. It is worth quoting:

Almost every absolute change, and the absolute component of almost every economic and social change or trend, points in a positive direction, as long as we view the matter over a reasonably long period of time. That is, all aspects of material human welfare are improving in the aggregate.

And he offers to bet a week's or a month's pay that these improving trends will continue indefinitely. Many indicators support his contention that there have been unquestioned improvements in the past, but it may be an unwise man who bets on the future. As Simon shows, life expectancy has increased enormously, the real price of resources - one indicator of scarcity - has fallen, literacy has improved, nutrition has improved, pollution has declined. Some of the indicators are global but some are peculiarly parochial. There is no mention, for example, of the fact that the average increase in per capita gross national product was close to zero for the 40 or so lowest income countries in the world between 1980 and 1993, excluding China and India. Perhaps this is too short a period to detect a long-run trend. Where the numbers do not support the case, the numbers are questioned. Concern about species extinction, for example, is an "environmentalist scam". Simon, writing an essay with the late Aaron Wildavsky, may be right to question the generality of 'biogeographical' or 'species-area' theories of extinction whereby extinction is inferred, not observed, from data on land-use conversions. And he is right to say that the actual recorded rate of extinction is around one species a year since 1600 , a result confirmed in the United Nations Environmental Programme's recent Global Biodiversity Assessment. This hardly seems dramatic. But more to the point is the number of threatened species today more than 5,000 animal species and some 26,000 plant species - and the rate at which known species go from being unthreatened to threatened. This is the view adopted by Holdgate, and on this basis it is hard to be as sanguine as Simon.

There are good features of The State of Humanity. First, it contains a mass of information and some of it will be unfamiliar. Second, there are some thoughtful and fascinating essays, for example on an analysis of long-term trends in suicides, on long-term trends in standards of living and 
on inequality in the United States (although this neglects the startling reversal in the past few decades). Third, it rightly takes to task the self-appointed doomsters who perhaps do not deliberately exaggerate, but who exaggerate because of poor research and inadequate questioning. The general laissez-faire tone of the volume will offend some, but, if so, the offended should be prepared to answer the case made in the book.

Holdgate accepts there is an array of environmental problems and spends more time telling us what has to be done. The recommendations are familiar but no less important for that: empowering communities, moving from outright conservation to sustainable use, education and new alliances between interest groups. $\mathrm{He}$ is sincere in his belief that we need a 'new ethic' of care, but the menu of action looks strangely naive: building a new conscience and spirituality, reforming the international economic order, and "new economic thinking" (when we have hardly made use of the power of the 'old' economic thinking) to improve our lot and the lot of other species.

Holdgate's volume is a worthwhile read but it has an inner risk. Spiritual shopping lists calling for 'changes in values' invite others to philosophize and debate while the environment burns. Holdgate is wise enough to see some of this risk and he calls for other action too. But one wonders if the dreamers really understand that it is all about competition between humans and other species for space, for a slice of the Earth. Until environmental assets secure economic value greater than that embodied in the competing uses of the land on which they rely, the state of humanity really is at risk, as much, it seems, from the concerned as from the benign optimists.

David Pearce is at the Centre for Social and Economic Research on the Global Environment, University College London, Gower Street, London WC1E 6BT, UK.

\begin{tabular}{|l|}
\hline \multicolumn{1}{|c|}{ New in paperback } \\
The Strange Case of the Spotted Mice \\
and Other Classic Essays on Science by \\
Peter Medawar. OUP, £7.99. \\
From Here to Infinity: A Guide to Today's \\
Mathematics by lan Stewart. OUP, \\
£7.99. A revised and retitled edition of \\
The Problems of Mathematics. \\
Natural Acts: A Sidelong View of \\
Science and Nature by David \\
Quammen. Avon, \$11. "Quammen's \\
book is full of strange information about \\
animals and their habitat, about Tycho \\
Brahe's artificial nose, and other such \\
oddities. His exuberance carries one, \\
sometimes unwillingly, along”, wrote \\
Walter Gratzer in a review in Nature $\mathbf{3 1 8}$, \\
116 (1985).
\end{tabular}

\section{Reality bites}

\section{Freeman J. Dyson}

The End of the World: The Science and Ethics of Human Extinction. By John Leslie. Routledge: 1996. Pp. 305. 16.99, \$23. To be published in the United States in May.

THE subject of this book is a philosophical speculation that the author calls the "doomsday argument". The same speculation was independently put forward in Nature $(363,315 ; 1993)$ by Richard Gott, who gave it the more appropriate name of the Copernican principle. The idea is to estimate the probability of the survival of the human species by using the Bayes rule. The Bayes rule says that (probability of A) multiplied by (probability of $B$ given $A$ ) is equal to (probability of $B$ ) multiplied by (probability of $A$ given $B$ ). The rule is supposed to apply to any two hypotheses $\mathrm{A}$ and $\mathrm{B}$, because both sides of the equation are equal to the probability of the hypothesis (A and B). Formally, the rule is almost a tautology. But when it is applied to hypotheses in the real world, it can easily lead to absurd conclusions, because of ambiguities in the meaning of probability. Every estimate of probability must be based on a certain division of the world into known and unknown. The Bayes rule is valid only if the four probabilities in the equation are all based on the same division of the world. The phrase (probability of A) has no absolute meaning independent of previous knowledge.

Leslie applies the Bayes rule to a variety of situations of which the following is typical. Hypothesis A says that the human species will ultimately give birth to less than $X$ people. Hypothesis B says that Leslie and his readers live at a time when the human species has given birth to fewer than $Y$ people. Evidence from history and palaeontology indicates that (probability of B) is close to unity when $Y$ is of the order of a hundred billion. Also, (probability of A) cannot exceed unity. Thus the rule implies that (probability of A given B) does not exceed (probability of $B$ given A). Now, the probability that Leslie and his generation should happen to be among the first $Y$ people in order of birth, out of a total population greater than $X$, is less than $Y / X$. That is to say, (probability of $\mathrm{B}$ given $\mathrm{A}$ ) is less than $Y / X$. Therefore the Bayes rule leads to the conclusion that (probability of $\mathrm{A}$ given $\mathrm{B}$ ) is also less than $Y / X$. That is to say, there is less than a ten- per-cent chance that the human species will survive long enough to give birth to a trillion people. The conclusion is that our species has only a ten-per-cent chance of surviving as long as five hundred genera- tions with our present size of population, or fewer than five hundred generations if the population grows larger. Leslie elaborates this conclusion with numerous variations. He examines many different hypotheses and deduces the corresponding probabilities of survival. But the essential core of his reasoning is as I have stated it. The reasoning stands or falls according to whether the application of the Bayes rule is valid or invalid.

After careful consideration, I state unequivocally that the application of the Bayes rule is here invalid. The reason the rule fails is simple. The two quantities (probability of B) and (probability of B given $\mathrm{A}$ ) are not based on the same division of the world into known and unknown. When we estimate (probability of B) to be close to unity, we assume that we know enough about palaeontology to be sure that we are living among the first hundred billion humans. When we estimate (probability of $B$ given $A$ ) to be small, we assume that we know nothing of our place in the history of our species. The two estimates of probability are based on incompatible assumptions and are therefore not comparable. The application of the Bayes rule is invalid because the rules of the probability game have been changed between the left and right sides of the equation.

Half of the book is devoted to theoretical discussion of the Bayes rule and its application to the question of human survival. This discussion is worthless, being based on an invalid use of the rule. The other half of the book is a recital of the many real dangers to which our species is exposed. Here Leslie has nothing new to add. He refers to a large number of sources from the literature of science and risk assessment, but does not examine them critically.

Almost two hundred years ago, in 1798, Robert Malthus published his famous Essay on the Principle of Population as It Affects the Future Improvement of Society, deducing dire predictions of future misery from two hypotheses that he called the geometrical increase of population and the arithmetical increase of subsistence. His predictions of inevitable poverty failed because his hypotheses were faulty. The increase of subsistence turned out to be much faster than arithmetical. Nevertheless, uncritical belief in Malthus's predictions helped to hold back political and social progress in Britain for a century. Because of this unhappy precedent, I consider it important to call attention to the fallacy in Leslie's argument. A mistaken philosophical argument may have serious consequences in the real world.

Freeman J. Dyson is at the Institute for Advanced Study, Princeton, New Jersey 08540, USA. 